\title{
IDÉIAS
}

\section{Tradição Frustrante, Senão Catastrófica}

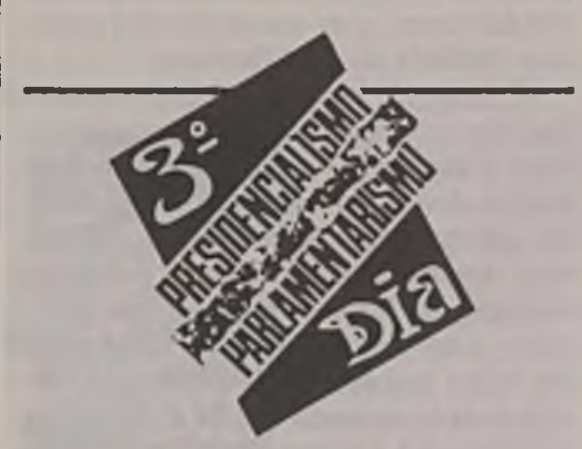

Permito-me uma reflexão, e fazer algumas observaçōes. Em primeiro lugar, acho que há uma tendência, ou houve uma tendência acima de tudo, dos conferencistas e debatedores, de confundir as causas com os efeitos. Isso é um mal brasileiro comum, mas eu vejo também que é um mal que afeta alemães e portugueses. As formas de governo são originárias de necessidades nacionais, políticas e até regionais. A democracia americana não é fruto de uma reflexão política, mas sim de uma necessidade pragmática que aqueles fundadores da Nação americana encontraram. Eles tiveram que resolver tudo de maneira pragmática. E o modelo americano, sobretudo nos EUA, consiste na presença de um Presidente muito forte ao lado de um Congresso muito forte. Isso porque os colonizadores americanos traziam a experiência inglesa de um período absolutista, e não se pode copiar um modelo sem as mesmas origens históricas.

A tradição presidencialista brasileira tem sido extremamente frustrante quando não catastrófica. Por outro lado, a adoção do parlamentarismo encontraria, a meu ver, obstáculos praticamente insuperáveis. $\mathrm{O}$ primeiro deles é que seria necessário englobar todos os ministérios militares num só ministério da Defesa, subordinado, portanto, às regras do Congresso. Eu acho que se isso ai acontecesse, pode-se até votar o par-

Cláudio Abramo é jornalista, articulista e integrante do Conselho Editorial da "Folha de Såo Paulo".

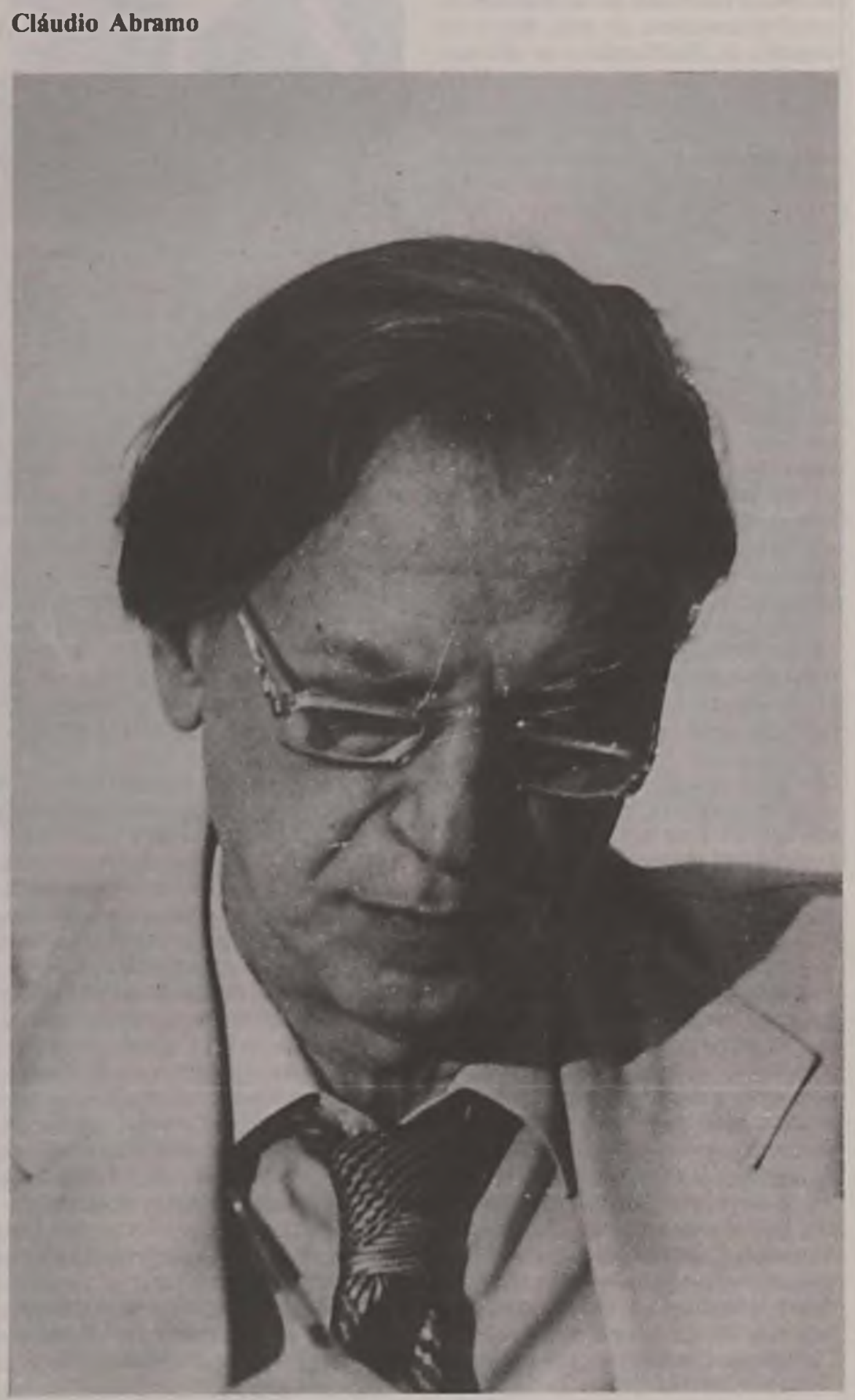




\section{IDÉIAS}

lamentarismo, mas não se tira esse ministério dos militares. Creio, então, que esse é um exercício abstrato, a menos que se faça um trabalho político muito amplo. O Chefe do Serviço de Informaçōes seria um funcionário comum do governo, e essas são, para mim, dificuldades praticamente insuperáveis.

Eu acho que, quando eu sublinhei que nós estamos confundindo efeito com causa, o problema básico brasileiro não é o parlamentarismo ou o presidencialismo, o problema básico brasileiro é formado pela presença de cerca de 100 milhōes de miseráveis ao lado de alguns milhões de privilegiados. A presença dessas duas contradições incorrigiveis no Brasil moderno, sem uma revolução, impede qualquer solução fora de crises continuadas, crises cíclicas, econômicas, politicas e institucionais.

Nós vamos ter repetições periódicas de crises - crise econômica, inflação, recessão, fundo monetário, dívida externa, crise política e crise institucional - , se não fizermos um programa de governo, seja sob que sistema for, presidencialista ou parlamentarista, que procure eliminar ou reduzir enfaticamente o abismo que existe entre as populaçōes: miserável, famélica, ignorante e manipulada pelos meios de comunicação. Quer dizer, todas as soluções serão inúteis sem que se procure resolver primeiro esse problema. Depois a sociedade procurará encontrar o caminho melhor para ela.

Eu queria chamar a atenção, aqui, para os que, por coincidência, pelos azares da providência, falaram aqui antes de nós: um representante da Alemanha e um representante de Portugal, que são paises que têm tradições autoritárias muito acentuadas. Na Alemanha não é só com Hitler, é também com Bismark. E em Portugal, onde, eu creio, houve a ditadura mais longa da história. Salazar caiu porque caiu da cadeira, literalmente. Quebrou as pernas, quebrou a cabeça. E foi substituído sintomaticamente por um Professor de Direito que era tão fascista ou mais fascista do que o Salazar. A solução que se deu à revolução portuguesa é uma solução típica de um país subdesenvolvido. Quer dizer, o país podia marchar para uma reforma total das suas estruturas, mas a interferência do imperialismo americano e dos interesses oci-

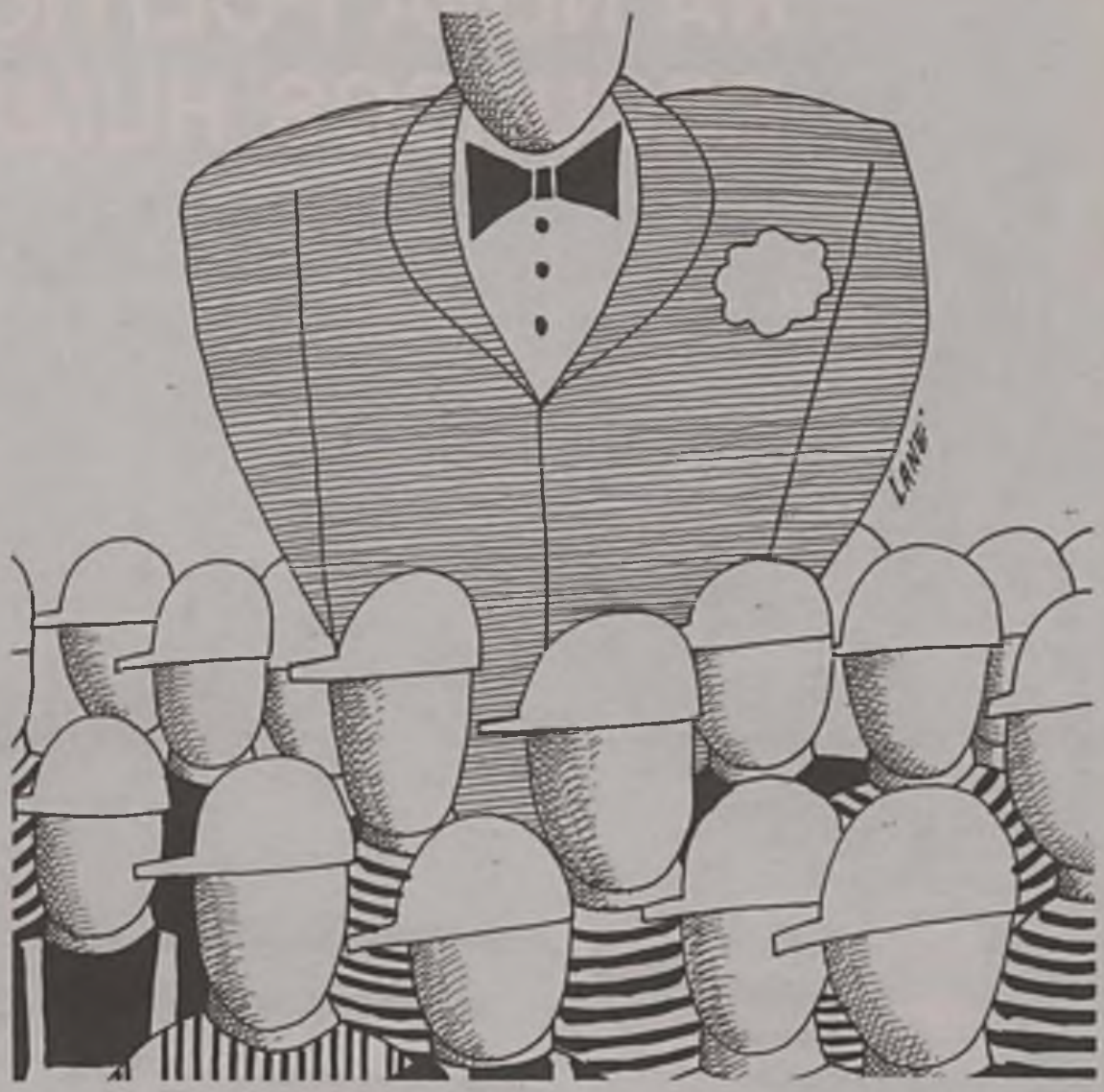

dentais mudaram o curso da história em Portugal. Portugal hoje tem um governo de meio-termo e alinhado com os países ocidentais, como tem a Alemanha. Quer dizer, nenhum problema fundamental deste pais foi tocado. A posição deles hoje é a mesma que era an-

tes da Segunda Guerra Mundial. Basicamente não mudou nada.

Falou-se aqui na Itália. Eu queria chamar a atenção aqui do meu amigo Afif Domingos, que a Itália tem - você esqueceu um detalhe muito importante - um poderoso movimento democrata-cristão, embasado em raizes doutrinárias muito densas, e tem um fortíssimo Partido Comunista que tem filósofos e pensadores desde o começo do século. De modo que a sociedade italiana não é fruto apenas do espírito anarquista que se atribui aos italianos. Ela é resultado da presença de duas forças ideológicas muito definidas e com uma estrutura que, se ficasse poderosa, seria uma altíssima consciência política. É preciso lembrar também que, ao cuntrário da Alemanha, na Itália a resistência ao fascismo não cessou um dia só, porque caiu o Mussolini por uma solução tipicamente italiana, numa reunião do Conselho, onde os partidos clandestinos estavam perfeitamente organizados bem à luz do dia. Eu acho que ešsas configurações são necessárias. 